\title{
D-lactic acidosis secondary to short bowel syndrome
}

\author{
D L Zhang, Z W Jiang, J Jiang, B Cao, J S Li
}

Postgrad Med J 2003;79:1 10-112

A 12 year old boy presented with 11 episodes of weakness, ataxia, nausea, slurred speech, dehydration, and sometimes severe lethargy bordering on coma. A year previously the boy had small intestinal resections leaving $20 \mathrm{~cm}$ of small bowel remaining. D-lactic acidosis was diagnosed on the basis of a D-lactate level of 5.23 $\mathrm{mmol} / \mathrm{I}$. The clinical presentation of the disease is recurrent episodes of unusual neurological manifestations and severe metabolic acidosis. The diagnosis is dependent on the presentations and the plasma D-lactate level. Development of the syndrome seems to be the effect of the accumulation of D-lactic acid.

\begin{tabular}{|c|c|}
\hline Symptoms and signs & Investigations \\
\hline $\begin{array}{l}\text { Weakness, nausea, } \\
\text { slurred speech, } \\
\text { lethargic and hostile, } \\
\text { blood pressure } 75 / 50 \\
\text { mm Hg on sitting, } \\
\text { ataxia, dehydration, } \\
\text { asterixis }\end{array}$ & $\begin{array}{l}\mathrm{pH} 7.21 \\
\text { Potassium } 4.9 \mathrm{mmol} / \mathrm{I} \\
\text { Sodium } 140 \mathrm{mmol} / \mathrm{I} \\
\text { Chloride } 110 \mathrm{mmol} / / \\
\text { Bicarbonate } 6 \mathrm{mmol} / \mathrm{I} \\
\text { D(-)-lactate level } 5.23 \\
\text { mmol/l } \\
\text { Anion gap } 24 \text { * }\end{array}$ \\
\hline
\end{tabular}

anastomosis of the proximal $10 \mathrm{~cm}$ of jejunum to the distal 10 $\mathrm{cm}$ of ileum. The colon and ileocecal valve were normal. Subsequently, parenteral nutrition was used intermittently in order to help the patient maintain his weight and nutritional status.

At the time of referral the patient was given 5\% bicarbonate $(100 \mathrm{ml})$ intravenously as well as rehydration, but the anion gap was still outside the normal limit and the patient remained weak, ataxic, nauseated, and his speech was slurred. A total of $500 \mathrm{ml}$ bicarbonate was given because of progressive acidosis (table 2). In spite of the therapy, an increase in the anion gap was still seen. In view of the patient's short intestine and normal colon, and an unexplained anion gap metabolic acidosis, D-lactic acidosis was suspected. On the next day, a sample of peripheral venous blood had a $\mathrm{pH}$ of 7.24 , the plasma $\mathrm{L}(+)$-lactate concentration was $6.12 \mathrm{mmol} / \mathrm{l}$ and the $\mathrm{D}(-)$-lactate was $5.23 \mathrm{mmol} / \mathrm{l}$ (normal $<0.2 \mathrm{mmol} / \mathrm{l}$ ). The patient was receiving oral neomycin $100 \mathrm{mg} / \mathrm{kg} /$ day. Since the presumed source of D-lactate was bacterial fermentation, oral intake was stopped and total parenteral nutrition was undertaken. Two days later the patient's weakness, ataxia, nausea, and slurred speech had improved. Five days after admission his symptoms disappeared and physical examination was normal. On the 15th hospital day, the plasma $\mathrm{D}(-)$-lactate concentration was $1.72 \mathrm{mmol} / \mathrm{l}$. Next day the patient was discharged from hospital with instructions to decrease his carbohydrate intake and to restrict his intake of foods such as pickles, yogurt, and sauerkraut. No more attacks happened in two months of follow up.

\section{Method of measuring lactate}

Enzymatic measurement of $\mathrm{L}(+)$-lactate was done by a standard method using lactate dehydrogenase from rabbit muscle. Enzymatic analysis of D(-)-lactate was done the same way except that the $\mathrm{L}(+)$-lactate standard and $\mathrm{L}(+)$-lactate dehydrogenase were substituted by $\mathrm{D}(-)$-lactate and $\mathrm{D}(-)$ lactate dehydrogenase respectively (obtained from Sigma Chemical Co, St Louis, Missouri).

\section{DISCUSSION}

\section{Clinical presentations}

The clinical presentation is characterised by recurrent episodes of unusual neurological manifestations and severe 
Table 2 Treatment options of the patient

\begin{tabular}{llllll}
\hline Options & Admission & Day 1 & Day 2 & Day 5 & Day 5-15 \\
\hline Rehydration $(\mathrm{ml})$ & 3100 & 2500 & 2150 & 2150 & \\
$5 \%$ Bicarbonate $(\mathrm{ml})$ & 500 & 375 & 125 & 125 & \\
Diet & Low carbohydrate & Fasting & Fasting & Fasting & Low carbohydrate \\
Neomycin $(\mathrm{mg} / \mathrm{kg})$ & & 100 & 100 & 100 & 50 \\
TPN (kcal/kg) & 25 & 30 & 30 & \\
\hline TPN, total parenteral nutrition. & & & & \\
\end{tabular}

metabolic acidosis. These episodes often last from a few hours to several days. The patients often have short bowel syndrome, mainly due to surgical resection of intestine or intestinal bypass surgery for treatment of obesity. Another underlying condition is chronic exocrine pancreatic insufficiency. D-lactic acidosis can present from a few months to 23 years after the underlying condition. ${ }^{2}$ Neurological manifestations are nearly always present, but their degree varies from patient to patient Common features include slurred speech, confusion, inability to concentrate, somnolence, hallucinations, clumsiness, weakness, ataxia, unsteady gait, nystagmus, irritability, and abusive behaviour. ${ }^{3}$ In this report, the patient had short bowel syndrome due to surgical resection of his intestine. D-lactic acidosis presented nearly a year later. His main symptoms were episodes of weakness, ataxia, nausea, slurred speech, dehydration, and sometimes severe lethargy bordering on coma. The patient presented with systemic acidosis; however, there have been reports of D-lactic acidosis without systemic acidosis.

\section{Metabolism of lactate}

D-lactate and L-lactate are optical isomers. D-lactic acid found in human physiological fluids originates from bacterial production in the intestinal tract, from D-lactate ingestion, or from endogenous production by the methylglyoxylase pathway. ${ }^{4}$ Other sources of D-lactate are dietary intake and medical administration of parenteral solutions containing DL-lactate, such as peritoneal dialysis and lactated Ringer solution. ${ }^{5}$ L-lactate, an end product of glycolysis, is the predominant form of lactate, and usually present as a microconstituent in the blood and muscle fluids of humans and other vertebrate animals. In addition, DL-lactic acid widely exists in nature. It is formed in sour milk by lactic acid bacteria, and in molasses due to partial conversion of sugars. It is also distributed in apples, tomatoes, beer, wines, opium, ergot, foxgloves, and other higher plants especially during germination. ${ }^{6}$ L-lactate and D-lactate are both produced from and metabolised to pyruvate by the enzyme lactic dehydrogenase. The production and metabolism of L-lactate needs L-lactic dehydrogenase, and that of D-lactate needs D-lactic dehydrogenase. After absorption of both isomers, only D-lactate accumulates because of its lower metabolism due to a lack of specific metabolising enzymes ${ }^{78}$ and its slower renal clearance. ${ }^{9-11}$ It is clear that in humans who have no D-lactic dehydrogenase, the D-2-hydroxyacid dehydrogenase that converts D-lactic acid to pyruvate in humans is likely to be responsible for metabolism. The enzyme is in high concentrations in the liver and kidney of humans and some other animals. ${ }^{12}$ Most data suggest that humans could efficiently metabolise D-lactate. ${ }^{13}$ In fact, no case of D-lactic acidosis in normal humans due to an intake of food containing D-lactic acid has been reported in the literature.

\section{Pathophysiology of D-lactic acidosis}

Because of its slower metabolism, only D-lactate accumulates and remains distributed in the human body as a low molecular weight organic acid until it is excreted unchanged in the urine. The clinical presentation of D-lactic acidosis seems to be the direct or indirect effect of the accumulation of D-lactic acid, and an intestinal origin for the disorder can be postulated. Above all, a prerequisite for this disorder is a short bowel abnormality. In patients with short bowel syndrome, carbohydrates that normally undergo sterile digestion in the small bowel reach the colon in undigested or partially digested form and are fermented to produce organic acids. This results in a progressive decrease in intraluminal $\mathrm{pH}$, which alters the intestinal microenvironment favouring the overgrowth of acid resistant bacteria such as Lactobacillus acidophilus, Lactobacillus fermenti, and streptococcus. These are the main bacteria that produce D-lactate in both animals and humans. ${ }^{14}{ }^{15}$ Secondly, stool flora show a preponderance of Gram positive anaerobes, which are the major lactate producers. The effect of poorly absorbed oral antibiotic was good in most patients with D-lactic acidosis. Finally, the symptoms of D-lactic acidosis may also occur after patients injest a large amount of carbohydrate. Diminished colonic motility that allows time for nutrients in the colon to undergo bacterial fermentation, deficiency of thiamine, ${ }^{16}$ and impaired D-lactate metabolism may be other reasons for the development of D-lactate acidosis.

Why does D-lactate acidosis bring about neurological symptoms? It is difficult to explain them by the acidosis itself, as patients with other types of acidosis of comparable severity do not have such presentations. It is possible that D-lactate itself is toxic to the brain. The brain apparently lacks D-2-hydroxyacid dehydrogenase, and D-lactic acid may accumulate excessively there. High D-lactic acid level may alter intraneuronal $\mathrm{pH}$. Low $\mathrm{pH}$ inhibits pyruvate decarboxylation by interfering with the pyruvate dehydrogenase complex and therefore decreases production of acetyl CoA and adenosine triphosphate, an outcome that leads to altered neurotransmitter production. Because the cerebellum contains minimal pyruvate dehydrogenase reserves over that needed for normal metabolism, cerebellar manifestations may be especially prominent in in D-lactic acidosis. ${ }^{17}$ Acquired and congenital disorders of pyruvate metabolism generally present with central nervous system symptoms. ${ }^{18}{ }^{19}$ However, some men acting as controls in a test didn't have neurological symptoms when their plasma D-lactate levels reached $3.5 \mathrm{mmol} / \mathrm{l} .{ }^{9}$ It is likely that there are some other reasons for the cause of the patient's neurological presentation.

\section{Diagnosis}

Noticeably, there needs to be emphasis on the fact that the colon needs to be present for D-lactic acidosis to occur. If the patient has short bowel syndrome or chronic exocrine pancreatic insufficiency with a high level of D-lactate, we should suspect D-lactic acidosis. However there are no universal reference values for D-lactate at present. L-lactic acidosis is commonly defined by a serum level of lactate greater than 5 $\mathrm{mmol} / \mathrm{l}{ }^{20}$ In contrast, D-lactate is normally undetectable, and the measured concentration of D-lactate in excess of $3 \mathrm{mmol} / \mathrm{l}$ contributes greatly to the acidosis.

\section{Treatment}

So far there are no effective therapies. In some cases antibiotics can control symptoms and prevent recurrences of the syndrome, but have no effect in other patients. Indeed, some 


\section{Key points}

- D-lactic acidosis should be looked for in cases of metabolic acidosis in which the identity of acidosis is not apparent and the patient has short bowel syndrome or chronic exocrine pancreatic insufficiency with high level of D-lactate.

- The clinical presentation is characterised by episodes of peculiar neurological manifestations and severe metabolic acidosis.

- In this patient D-lactic acidosis was diagnosed on the basis of D-lactate level of $5 \mathrm{mmol} / \mathrm{I}$ and clinical presentations.

- Low carbohydrate diets, bicarbonate given intravenously as well as rehydration, and taking poorly absorbed oral antibiotics may be helpful to control symptoms.

patients presented with the above syndrome while taking antibiotics. ${ }^{22}{ }^{22}$ This may be because antibiotics promote the overgrowth of D-lactate-producing bacteria at the expense of other competing bowel flora. We recommend that the treatment methods should include a low carbohydrate diet, bicarbonate given intravenously as well as rehydration, correction of the underlying conditions if possible, a saline enema if constipated, and poorly absorbed oral antibiotics when necessary. Administration of insulin to diminish fatty acid levels and enhance D-lactate clearance may be a treatment option during an episodes of acidosis. ${ }^{23}{ }^{24}$ If the patient is in a critical condition, haemodialysis is also likely to be an effective therapy.

\section{Authors' affiliations}

D L Zhang, Z W Jiang, J Jiang, B Cao, J S Li, Research Institute of General Surgery, School of Medicine, Nanjing University, Nanjing, Peoples Republic of China

Correspondence to: Dr Zhang Dianliang, Research Institute of General Surgery, Jinling Hospital, 305 East Zhongshan Road, Nanjing 210002 , Peoples Republic of China; phdzdl@yahoo.com

Submitted 8 January 2002

Accepted 27 June 2002

\section{REFERENCES}

1 Oh MS, Phelps KR, Traube M, et al. D-lactic acidosis in a man with the short-bowel syndrome. N Engl J Med 1979;301:249-52.

2 Narula RK, El Shafei A, Ramaiah D, et al. D-lactic acidosis 23 years after jejuno-ileal bypass. Am J Kidney Dis 2000;36:E9.

3 Uribarri J, Oh MS, Carroll HJ. D-lactic acidosis: a review of clinical presentation, biochemical features, and pathophysiologic mechanisms. Medicine 1998;77:73-82

4 Thornalley PJ. Pharmacology of methylglyoxal: formation, modification of proteins and nucleic acids, and enzymatic detoxification - a role in pathogenesis and antiproliferative chemotherapy. Gen Pharmacol 1996;27:565-73.

5 Chan L, Slater J, Hasbargen J, et al. Neurocardiac toxicity of racemic D, L-lactate fluids. Integr Physiol Behav Sci 1994;29:383-94.

6 Motonaka J, Katumoto Y, Ikaeda S. Preparation and properties of enzyme sensors for L-lactic and D-lactic acids in optical isomers. Analytica Chimica Acta 1998;368:91-5.

7 Tubbs PK. The metabolism of D- $\alpha$-hydroxy acids in animal tissue. Ann N Y Acad Sci 1965;119:920-6.

8 Cammak R. Assay, purification and properties of mammalian Cammak R. Assay, purification and properties
D-2-hydrogenase. Biochm J 1969;115:55-64.

9 De Vrese M, Koppenhoefer B, Barth CA. D-lactic acid metabolism after an oral load of DL-lactate. Clin Nutr 1990;9:23-8.

10 Oh MS, Uribarri J, Alveranga D, et al. Metabolism utilization and renal handling of D-lactate in men. Metabolism 1985;34:621-5.

11 Connor H, Woods HF, Ledingham JGG. Comparison of the kinetics and utilization of $\mathrm{D}(-)$ - and $\mathrm{L}(+)$-sodium lactate in normal man. Ann Nutr Metab 1983;27:481-7

12 Yasuda T, Ozawa S, Shiba C, et al. D-lactic metabolism in patients with chronic renal failure undergoing CAPD. Nephron 1993;63:416-22.

13 De Vrese M, Barth CA. Postprandial plasma d-lactate concentration after yogurt ingestion. Z Ernahrungswiss 1991;30:131-7.

14 Cross SA, Callaway CW. D-lactic acidosis and selected cerebellar ataxias. Mayo Clin Proc 1984;59:202-5.

15 Anonymous. The colon, the rumen, and D-lactic acidosis [editorial] Lancet 1990;336:599-600.

16 Hudson M, Pocknee R, Mowat NA. D-lactic acidosis in short bowel syndrome-an examination of possible mechanisms. Q J Med 1990:74:157-63.

17 Vella A, Farrugia G. D-lactic acidosis: pathologic consequence of saprophytism. Mayo Clin Proc 1998;73:451-6.

18 Naito $E$, Ito $M$, Takeda $E$, et al. Molecular analysis of abnormal pyruvate dehydrogenase in a patient with thiamine-responsive congenital lactic acidemia. Pediatr Res 1994;36:340-8.

19 Awta H, Endo F, Tanove A, et al. Characterization of a point mutation in the pyruvate dehydrogenase El alpha gene from two boys with primary lactic academia. J Inherit Metab Dis 1994;17:189-95

20 Midias NE. Lactic acidosis. Kidney Int 1986;29:752-74.

21 Coronado BE, Opal SM, Yoburn DC. Antibiotic-induced D-lactic acidosis. Ann Intern Med 1995;22:839-42.

22 Flourie B, Messing B, Bismuth E, et al. D-lactic acidosis and encephalopathy in short-bowel syndrome occurring during antibiotic treatment. Gastroenterol Clin Biol 1990;14:596-8.

23 Halperin ML, Kamel KS. D-lactic acidosis: turning sugar into acids in the gastrointestinal tract. Kidney Int 1996;49:1-8.

24 Bongaerts G, Tolboom J, Naber T, et al. D-lactic academia and aciduria in pediatric and adult patients with short bowel syndrome. Clin Chem 1995;41:107-10. 